Cite this: J. Mater. Chem. A, 2013, 1 , 1102

Received 12th November 2012 Accepted 12th November 2012

DOI: 10.1039/c2ta01068b www.rsc.org/MaterialsA
View Article Online

View Journal | View Issue

\title{
Tuning of gallery heights in a crystalline 2D carbon nitride networkt
}

\begin{abstract}
Samantha Y. Chong, ${ }^{a}$ James T. A. Jones, $\ddagger^{a}$ Yaroslav Z. Khimyak, ${ }^{b}$ Andrew I. Cooper, ${ }^{a}$ Arne Thomas, ${ }^{c}$ Markus Antonietti ${ }^{d}$ and Michael J. Bojdys ${ }^{\star a}$

Poly(triazine imide)-a 2D layered network-can be obtained as an intercalation compound with halides from the ionothermal condensation of dicyandiamide in a eutectic salt melt. The gallery height of the intercalated material can be tuned via the composition of the eutectic melt and by post-synthetic modification. Here, we report the synthesis of poly(triazine imide) with intercalated bromide ions ( $\mathrm{PTI} / \mathrm{Br}$ ) from a lithium bromide and potassium bromide salt melt. $\mathrm{PTI} / \mathrm{Br}$ has a hexagonal unit-cell $\left(P 6_{3} \mathrm{~cm}\right.$ (no. 185); $a=8.500390(68) \AA, c=7.04483(17) \AA$ ) that contains two layers of imide-bridged triazine $\left(\mathrm{C}_{3} \mathrm{~N}_{3}\right)$ units stacked in an $A B$-fashion as corroborated by solid-state NMR, FTIR spectroscopy and high-resolution TEM. By comparison with a recently reported material $\mathrm{PTI} / \mathrm{Li}^{+} \mathrm{Cl}^{-}$, prepared from a $\mathrm{LiCl} / \mathrm{KCl}$ eutectic, the layer-stacking distance in the analogous bromide material was expanded from $3.38 \AA$ to $3.52 \AA$ - an exceptionally large spacing for an aromatic, discotic system (cf. graphite $3.35 \AA$ ). Subsequent treatment of PTI/Br with concentrated ammonium fluoride yields poly(triazine imide) with intercalated fluoride ions (PTI/F) $\left(P 6_{3} / m\right.$ (no. 176); $a=8.4212(4) \AA, c=6.6381(5) \AA$ ) as a statistical phase mix with $\mathrm{PTI} / \mathrm{Br}$. Fluoride intercalation leads to a contraction of the gallery height to $3.32 \AA$, demonstrating that the gallery height is synthetically tuneable in these materials.
\end{abstract}

\section{Introduction}

The quest for carbon nitrides - and in particular their saturated, $\mathrm{sp}^{3}$-hybridised, crystalline allotropes-has remained topical for the last few decades because theory predicts exceptional mechanical properties for this class of materials. ${ }^{1-3}$ This research area has gained momentum in recent years from a different direction: the layered graphitic $(\mathrm{C}, \mathrm{N})$ materials are not only deemed to be potential precursors for the predicted high-density $\mathrm{sp}^{3}$-bonded phases, ${ }^{4-6}$ but also show interesting properties in their own right, such as metal-free catalytic and photocatalytic activity. ${ }^{3,7-11}$ Realisation of such two-dimensional, covalently bonded molecular sheets with a periodic structure is itself an interesting and challenging research target, ${ }^{12}$ as exemplified by

${ }^{a}$ University of Liverpool, Department of Chemistry and Centre for Materials Discovery, Crown Street, Liverpool, L69 7ZD, UK. E-mail:m.j.bojdys.02@cantab.net; Tel: +44 (0) 7863699856

${ }^{b}$ School of Pharmacy, University of East Anglia, Norwich Research Park, Norwich, NR4 7TJ, UK

${ }^{'}$ Technische Universität Berlin, Institut für Chemie, Sekr. C2, Hardenbergstrasse 40, 10623 Berlin, Germany

${ }^{d}$ Max Planck Institute of Colloids and Interfaces, Research Campus Golm, 14424 Potsdam, Germany

† Electronic supplementary information (ESI) available: Experimental (continued), characterisation methods, ${ }^{1} \mathrm{H}^{-13} \mathrm{C}$ CP/MAS NMR kinetics data. See DOI: $10.1039 / \mathrm{c} 2 \mathrm{ta} 01068 \mathrm{~b}$

$\ddagger$ Defence Science and Technology Laboratory (dstl), Porton Down, Salisbury, Wiltshire, SP4 0JQ, UK. the recent explosion in graphene research and the development of $2 \mathrm{D}$ covalent frameworks. ${ }^{13-19}$

Previous attempts at the bulk synthesis of carbon nitrides mostly failed on account of incomplete condensation or polymerisation of molecular precursors yielding non-stoichiometric, amorphous solids, as critically appraised in later years. ${ }^{20-23}$ Sundermeyer performed organic chemistry in molten salts in the 1960s, pointing out the good solvating properties of the eutectic mixture of $\mathrm{LiCl}$ and $\mathrm{KCl}$ with respect to nitrides, carbides, cyanides, cyanates and thiocyanates. ${ }^{24,25}$ Inorganic salt melts have also been utilised for the synthesis of extended, covalently bonded, organic frameworks. ${ }^{15,26-29}$ The use of eutectic salt melts as both solvent and structure-directing agent in the polycondensation and deamination reaction of dicyandiamide leads to the formation of a graphitic $(\mathrm{C}, \mathrm{N})$ material, ${ }^{30}$ which was recently confirmed to be poly(triazine imide) with intercalated lithium and chloride ions $\left(\mathrm{PTI} / \mathrm{Li}^{+} \mathrm{Cl}^{-}\right)$, a remarkably low hydrogen content, and unprecedented crystallinity. ${ }^{31} \mathrm{PTI} / \mathrm{Li}^{+} \mathrm{Cl}^{-}$ consists of extended $2 \mathrm{D}$ layers of covalently linked triazine $\left(\mathrm{C}_{3} \mathrm{~N}_{3}\right)$ units with a delocalized $\pi$-electron system via imide-bridges. The apparent structural analogy with graphite extends to the accessibility of the interlayer space to guest molecules. In the case of $\mathrm{PTI} / \mathrm{Li}^{+} \mathrm{Cl}^{-}$, chloride ions are found in the interstitial space between layers while $\mathrm{Li}^{+}$ions decorate the trigonal voids spanned by neighbouring triazine units.

Here we report that the gallery height in this layered graphitic $(\mathrm{C}, \mathrm{N})$ material can be tuned by the choice of the 
intercalated halide. A lithium bromide and potassium bromide eutectic was employed in an analogous fashion for the preparation of poly(triazine imide) to yield a layered intercalation compound with full substitution of chloride by bromide. Subsequent treatment of PTI/Br with concentrated ammonium fluoride distorts the inter-layer ordering and causes statistical replacement of bromide by fluoride anions. The exchange of guest anions is accompanied by expansion or deflation of stacking distances as a function of their ionic radii. Furthermore, swelling of PTI/halide galleries opens up a potential route to the exfoliation of this interesting $2 \mathrm{D}$ material.

\section{Experimental}

\section{Synthesis of PTI/Br}

Lithium bromide and potassium bromide eutectic $(\mathrm{LiBr} / \mathrm{KBr}$, $52: 48 \mathrm{wt} \%$, m.p. $348^{\circ} \mathrm{C}$ ) was prepared according to literature. ${ }^{32}$ Dicyandiamide ( $2 \mathrm{~g}, 23.79 \mathrm{mmol}$ ) was thoroughly ground with $10 \mathrm{~g}$ of $\mathrm{LiBr} / \mathrm{KBr}$. The reaction mixture was heated at $40 \mathrm{~K} \mathrm{~min}^{-1}$ under inert atmosphere and kept at the reaction temperature of $600^{\circ} \mathrm{C}$ for $48 \mathrm{~h}$. After natural cooling, excess salt was removed in boiling distilled water. The product was dried thoroughly at $200{ }^{\circ} \mathrm{C}$ under vacuum to yield PTI/Br (1.16 g, $6.29 \mathrm{mmol}, 79 \%$ yield) as a yellow-brown powder.

\section{Synthesis of PTI/F}

Poly(triazine imide) with intercalated bromide ions (PTI/Br) (200 mg, $1.08 \mathrm{mmol}$ ) was stirred and heated at $60{ }^{\circ} \mathrm{C}$ for $48 \mathrm{~h}$ in aqueous ammonium fluoride solution $(100 \mathrm{~mL}, 8 \mathrm{M})$. The solid was filtered off and washed repeatedly with distilled water. The yellow-brown powder was dried thoroughly at $200{ }^{\circ} \mathrm{C}$ under vacuum to yield a statistical mix of PTI/F and PTI/Br (42 mg, $0.67 \mathrm{mmol}, 62 \%$ yield).

\section{Results and discussion}

Elemental microanalysis and ICP of PTI/Br gave the following values: $\mathrm{C}, 32.6 ; \mathrm{N}, 56.4 ; \mathrm{H}, 0.97 ; \mathrm{O}, 4.7 ; \mathrm{Br}, 3.82$; and $\mathrm{Li}, 1.51 \mathrm{wt} \%$. An approximate composition of the material is $\mathrm{C}_{12} \mathrm{~N}_{17.8} \mathrm{H}_{4.3} \mathrm{Br}_{0.2} \mathrm{Li}_{1.0}$, with less bromide, lithium and nitrogen in comparison with $\mathrm{PTI} / \mathrm{Li}^{+} \mathrm{Cl}^{-}$and $\mathrm{C}_{6} \mathrm{~N}_{9} \mathrm{H}_{3} \cdot \mathrm{HCl}^{31,33,34}$ This is due in part to inhomogeneous distribution of halides and introduction of vacancies in the interstitial space brought about by the washing procedure.

ATR-FTIR spectroscopy of the material shows fairly broad features characteristic of a network (Fig. 1). The region from 1200 to $1600 \mathrm{~cm}^{-1}$ can be assigned to stretching modes of $(\mathrm{C}, \mathrm{N})$ heterocycles, and the sharp feature at $805 \mathrm{~cm}^{-1}$ is classically attributed to the out-of-plane breathing mode of triazine $\left(\mathrm{C}_{3} \mathrm{~N}_{3}\right)$ units. Peaks at 3300 and $3180 \mathrm{~cm}^{-1}$ indicative of secondary and primary amines (and their intermolecular H-bonding) can be discerned, which is in agreement with the results from elemental analysis.

Quantitative solid-state ${ }^{13} \mathrm{C}\left\{{ }^{1} \mathrm{H}\right\}$ magic-angle-spinning (MAS) NMR spectra of PTI/Br show three peaks at 167.9, 162.6 and $157.8 \mathrm{ppm}$ which are in broad agreement with the carbon environments found for $\mathrm{PTI} / \mathrm{Li}^{+} \mathrm{Cl}^{-}$(Fig. 2A). ${ }^{31}$ The resonance at

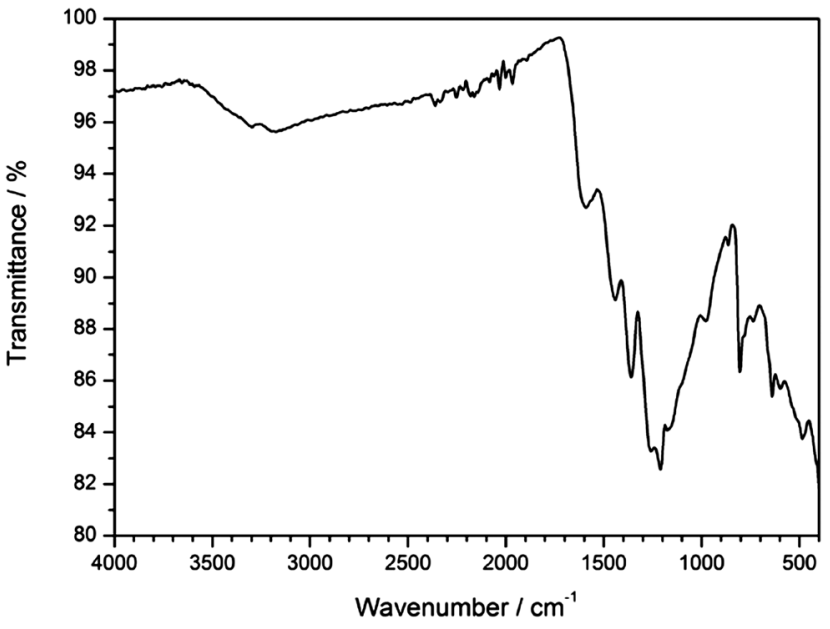

Fig. 1 ATR-FTIR spectrum of PTI/Br showing characteristic N-H stretches at 3300 and $3180 \mathrm{~cm}^{-1}$ as well as the breathing-mode of the triazine $\left(\mathrm{C}_{3} \mathrm{~N}_{3}\right)$ unit at $805 \mathrm{~cm}^{-1}$

$167.9 \mathrm{ppm}$ displays very slow CP kinetics and shows no evidence of relaxation in the rotating frame, which is typical for a carbon environment with very few protons in its proximity ( $c f$. Table S2, ESI $\dagger$ ). Hence, this signal can be assigned to the carbons in the triazine ring. The two resonances at 162.6 and $157.8 \mathrm{ppm}$ show CP kinetics typical of protonated aromatic environments, which can be attributed to the bridging imide-bonds, unreacted endgroups or phase impurities (Fig. 2B).

${ }^{1} \mathrm{H}^{-15} \mathrm{~N}$ CP/MAS NMR data shows three to four resonances similar to those reported for PTI $/ \mathrm{Li}^{+} \mathrm{Cl}^{-} .{ }^{31}$ The broad feature with principal maxima at 194.8 and $180.2 \mathrm{ppm}$ is in the region of ternary nitrogen environments. The broad resonance at $129.3 \mathrm{ppm}$ represents an NH-environment as confirmed by dipolar dephasing experiments conducted by Schnick et al. ${ }^{31} \mathrm{~A}$ weak shoulder at $138.0 \mathrm{ppm}$ is assigned to a split of the $\mathrm{NH}^{-}$ signal by $\mathrm{Li}^{+} / \mathrm{H}^{+}$disorder in the structure, but it can be assumed that most imide-bridges in $\mathrm{PTI} / \mathrm{Br}$ have no lithium ions in their environment in agreement with the deficiency of lithium in the elemental composition (Fig. 2C).

Transmission electron microscopy (TEM) and selected area electron diffraction (SAED) confirm hexagonal symmetry of PTI/ $\mathrm{Br}$ on molecular level with a lattice constant of $8.50 \AA$ in the $h k 0$ plane (Fig. 3B-D). The broad diffraction spots running diagonally across Fig. 3B correspond to real space distances of $3.52 \AA$ for the inner spot and $1.76 \AA$ for the outer spot and can be assigned to expected peaks ( $\left(\begin{array}{lll}0 & 0\end{array}\right)$ and $\left(\begin{array}{lll}0 & 0 & 4\end{array}\right)$, respectively, for a principal lattice constant $c=7.04 \AA$. Sharp peaks in the $h k 0$ plane and diffuse diffraction along the $00 \mathrm{l}$ direction suggest a high degree of in-plane order, but a level of disorder in the stacking arrangement of individual layers. This is confirmed in the micro-scale make-up of PTI/Br from SEM images (Fig. 3E and F). Although sheets of the material are discernible, they do not seem to form ordered stacks as might be expected.

Rietveld refinement of the powder X-ray diffraction (PXRD) pattern of $\mathrm{PTI} / \mathrm{Br}$ gave an atomic structure analogous to $\mathrm{PTI} / \mathrm{Li}^{+} \mathrm{Cl}^{-}$and $\mathrm{C}_{6} \mathrm{~N}_{9} \mathrm{H}_{3} \cdot \mathrm{HCl}$ based on a $2 \mathrm{D}$, planar arrangement of imide-linked triazine $\left(\mathrm{C}_{3} \mathrm{~N}_{3}\right)$ units (Fig. 4). The trigonal voids 

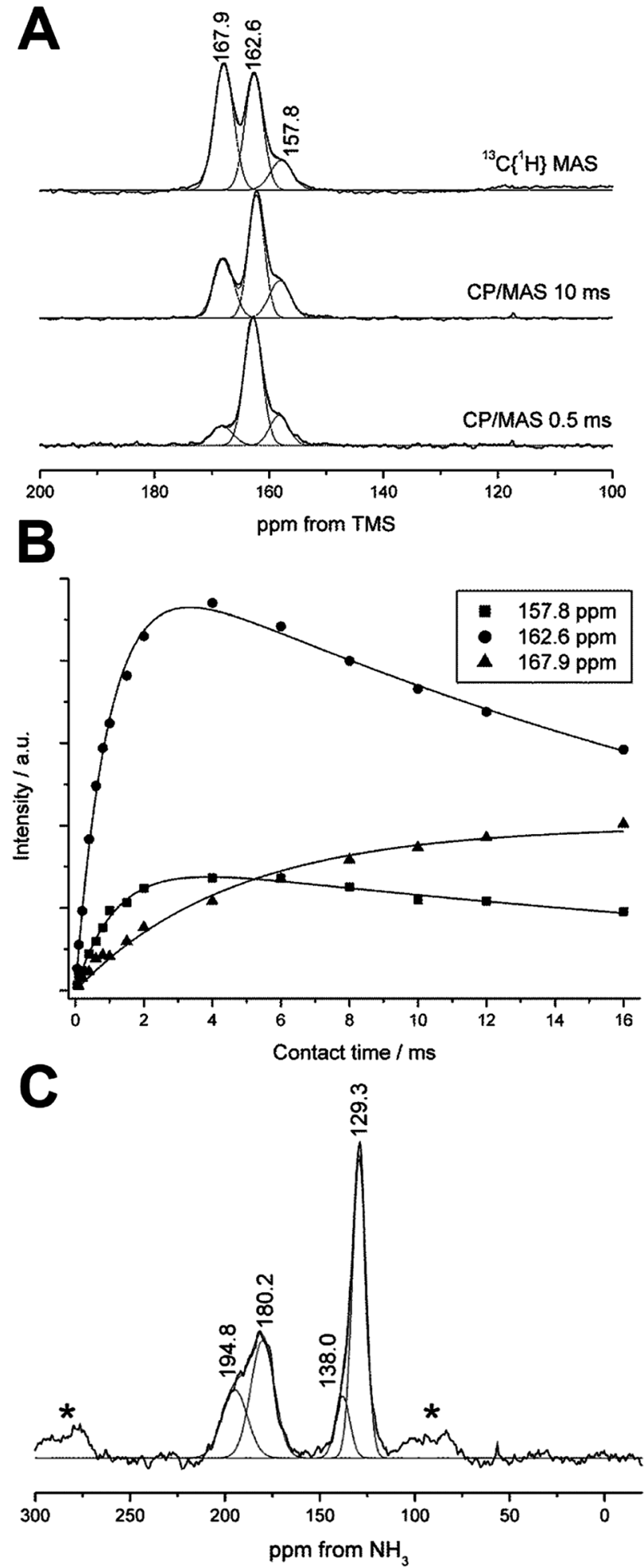

Fig. 2 Solid-state NMR investigation of $\mathrm{PTI} / \mathrm{Br}$ showing ${ }^{13} \mathrm{C}\left\{{ }^{1} \mathrm{H}\right\} \mathrm{MAS}$ and ${ }^{13} \mathrm{CCP} /$ MAS NMR spectra (A), ${ }^{13} \mathrm{C} C P /$ MAS NMR kinetics curves (B), and a ${ }^{1} \mathrm{H}-{ }^{15} \mathrm{~N} C P / M A S$ NMR spectrum ( $\tau=5 \mathrm{~ms}$ ) (C). Spinning side-bands are denoted with asterisks.

spanned by neighbouring triazine units are superimposed on top of each other, forming 1D pore channels that are decorated by the intercalated halides (Fig. 4B and C). Layers of the material are stacked in a graphitic, AB-fashion with the bromide anions situated in the interstitial space (Fig. 4D). This leads to
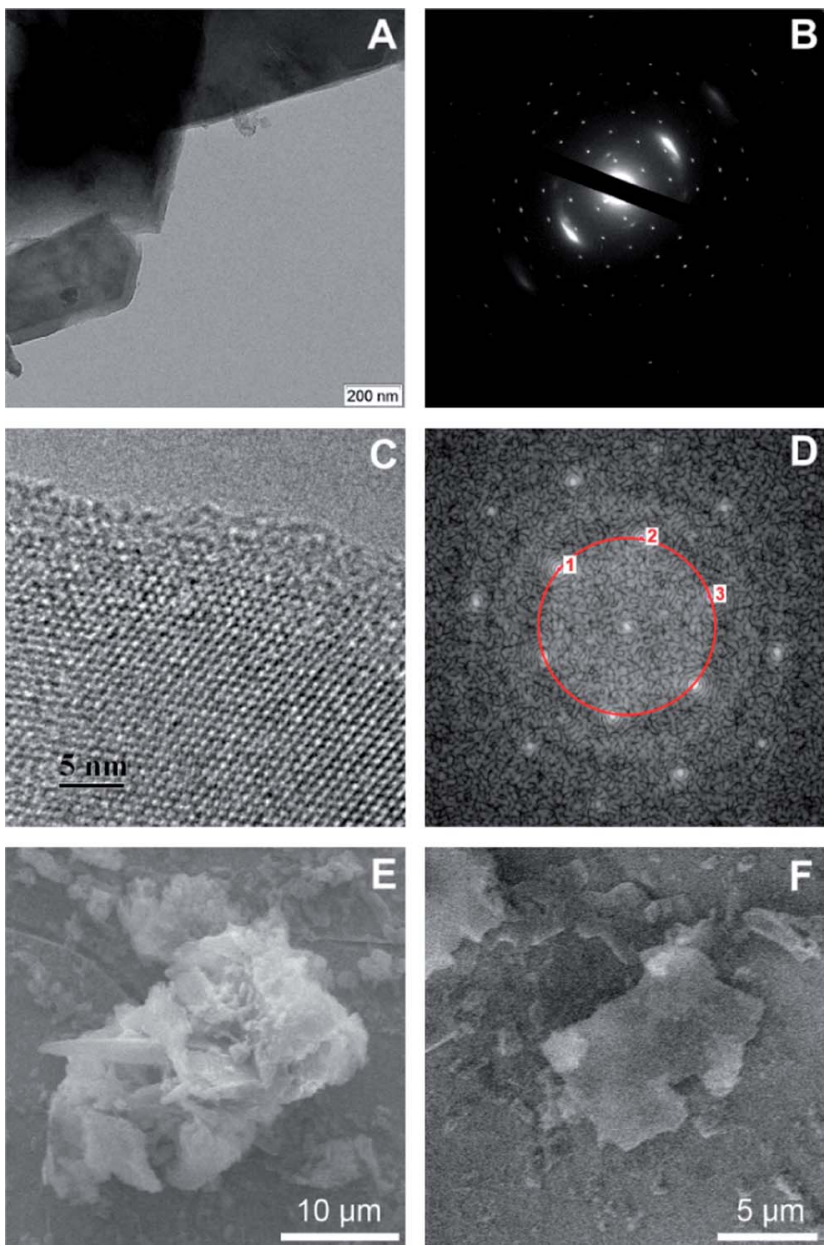

Fig. 3 Representative TEM image of PTI/Br showing sharp breaking edges with characteristic $120^{\circ}$ and $60^{\circ}$ angles (A), and corresponding SAED pattern (B). The hexagonal pattern in the $h k 0$ plane corresponds to a lattice constant of $a=8.50 \AA$ and the broad peaks along the 001 direction correspond to $c=7.04 \AA$. HRTEM image (C), and corresponding Fourier transform image (D); the red circle indicates a distance of $8.50 \AA$ in real space. Representative SEM images showing disordered platelets of $\mathrm{PTI} / \mathrm{Br}(\mathrm{E}$, and $\mathrm{F})$.

an expanded gallery height of $3.52 \AA$. The expansion of the stacking distance as compared to $\mathrm{PTI} / \mathrm{Li}^{+} \mathrm{Cl}^{-}$can be rationalised by considering the radii of the intercalated halide anions. Chlorine has a crystal radius of $1.67 \AA$ and an ionic radius of $1.81 \AA$, while for bromine the respective values are $1.82 \AA$ and $1.96 \AA \AA^{35,36}$ Replacing $\mathrm{Cl}$ for $\mathrm{Br}$ in a layered PTI-structure would hence give an increase of the radius of the guest of $0.15 \AA$ regardless of whether the electronic environment of the halide is more lattice crystalline or more ionic. This correlates closely with the actual increase of the gallery height of $0.14 \AA$, which corroborates that the halide anions must be (at least partially) situated in the interstitial space between layers.

Since the gallery height of PTI can be expanded with larger halide anions, decrease of stacking distance should be achievable with smaller anions. However, the use of a fluorine-based reaction medium or eutectic analogous to $\mathrm{LiCl} / \mathrm{KCl}$ and $\mathrm{LiBr} /$ $\mathrm{KBr}$ for the direct synthesis of a PTI with intercalated fluoride ions is impractical and potentially dangerous due to the likely formation of reactive fluoride-containing intermediates during 

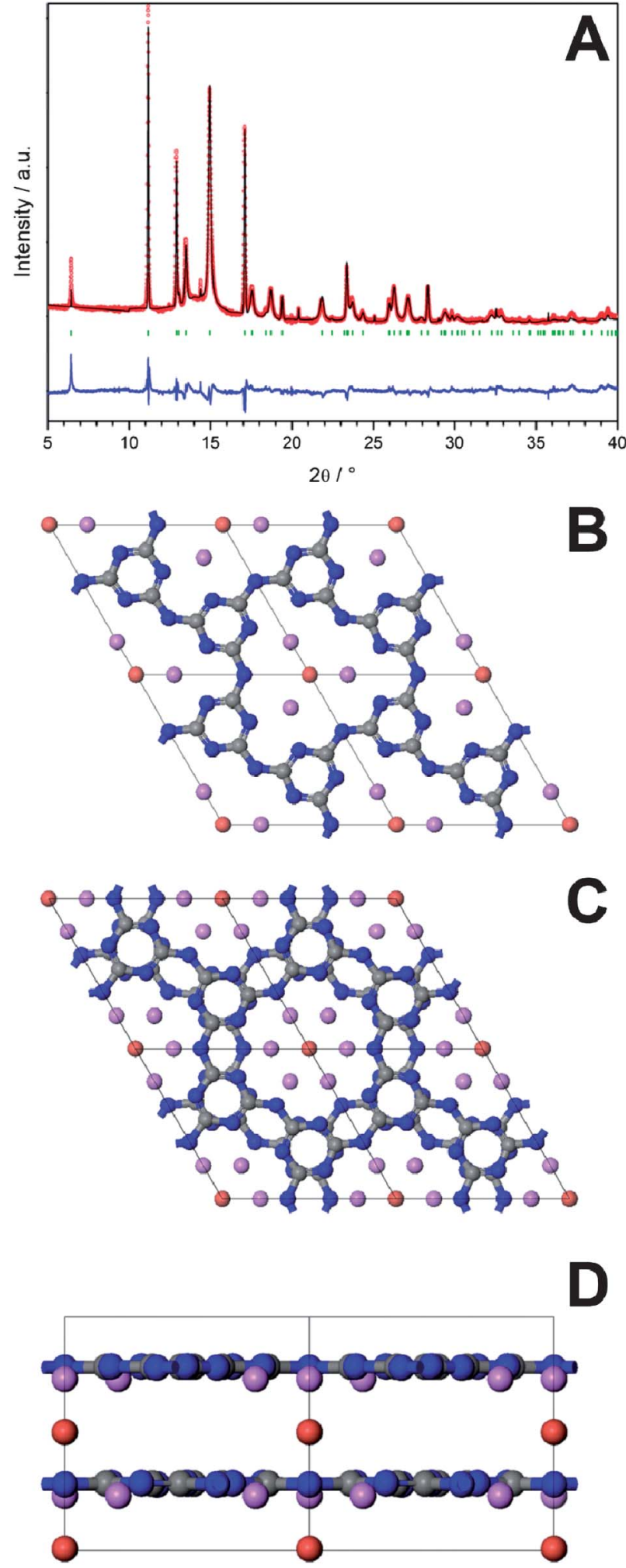

Fig. 4 Rietveld refinement performed on the PXRD pattern of $\mathrm{PTI} / \mathrm{Br}\left(R_{\mathrm{wp}}=\right.$ $2.20 \%, R_{\mathrm{p}}=1.74 \% \chi^{2}=3.72$ ) with the observed pattern in black, refined profile in red, difference plot in blue, and Bragg peak positions in green (A). Projection along the c-axis of one layer (B) and two consecutive layers (C) of PTI/Br with carbon, nitrogen, lithium and bromide atoms represented as grey, blue, purple and red spheres, respectively. Projection along the $b$-axis showing $\mathrm{Br}$-anions in the interlayer space $(D)$. The parameters of the hexagonal unit cell $\left(\mathrm{PG}_{3} \mathrm{Cm}, \mathrm{no} .185\right)$ are $a=8.500390(68) \AA, c=7.04483(17) \AA$.
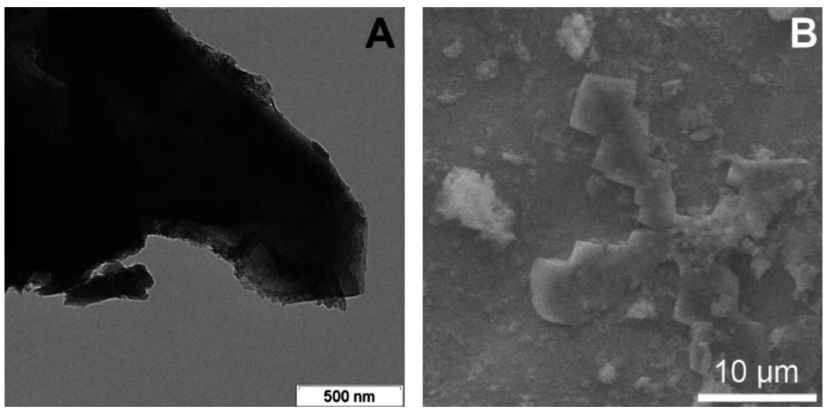

Fig. 5 Representative TEM (A), and SEM image (B) of a PTI/F and PTI/Br phasemix showing disordered platelets.

the ionothermal condensation and the corrosive properties of fluorides towards glass in general. Partial intercalation of fluoride anions into PTI can be achieved however via post-synthetic treatment of $\mathrm{PTI} / \mathrm{Br}$ with concentrated ammonium fluoride $\left(\mathrm{NH}_{4} \mathrm{~F}\right)$. Elemental microanalysis and ICP of the product gives a composition of $\mathrm{C}_{12} \mathrm{~N}_{16.4} \mathrm{H}_{6.2} \mathrm{Br}_{0.09} \mathrm{~F}_{1.73} \mathrm{Li}_{0.50}(\mathrm{C}, 32.2 ; \mathrm{N}, 51.4 ; \mathrm{H}$, 1.39; O, 5.2; Br, 1.77; F, 7.32; and Li, 0.78 wt\%), which hints at incomplete substitution. The micro-scale morphology of the product is not affected by the post-synthetic modification, and disordered platelets are visible in TEM and SEM (Fig. 5).

The PXRD pattern of the recovered product is shown in Fig. 6A. All peaks attributed to $h k 0$ peaks for $\mathrm{PTI} / \mathrm{Br}$ are present with essentially identical FWHM values, indicating that inplane order has been retained. Peaks with an $l$ component, however, show a significant broadening. Furthermore, new, broad features appear at 17.9, 26.9, 29.5, and 50.0 $(2 \theta, \mathrm{Cu} \mathrm{K} \alpha)$. These peaks can be rationalised assuming not only a different gallery height, but also a different stacking arrangement. The broadness of peaks with $l$ components renders direct methods of structure solution from PXRD unfeasible. However, the proposed phase, PTI/F, can be constructed in structural analogy to $\mathrm{C}_{6} \mathrm{~N}_{9} \mathrm{H}_{3} \cdot \mathrm{HCl}$, as it does not show the halide-containing 1D channels of $\mathrm{PTI} / \mathrm{Li}^{+} \mathrm{Cl}^{-}$and $\mathrm{PTI} / \mathrm{Br}$. The layers of PTI/F stack in an AB-fashion. Voids of layer A, however, lie on top of voids of the subsequent layer, B (Fig. 6C). The gallery height of PTI/F has been decreased to $3.32 \AA$ - a value smaller than that of graphite which has a stacking distance of $3.35 \AA$. It is unclear from PXRD to what extent the substitution of bromide by fluoride anions has proceeded, because the principle peak-positions in the observed PXRD pattern in Fig. 6A can be rationalised either as a phase-pure PTI/F with pronounced turbostratic disorder or as a mixture of PTI/F and PTI/Br ( $c f$. Bragg peak positions in Fig. 6A). In light of the results from elemental microanalysis, it is more probable to assume a mix of phases and a statistical substitution of guests in the PTI structure. Undoubtedly though, the interlayer distance of the PTI material has been substantially decreased from 3.52 to $3.32 \AA$, at least for part of the sample. This difference can be attributed to the size of the intercalated halides (F; crystal radius of 1.145 and ionic radius of $1.285 \AA$, Br; crystal radius of 1.82 and ionic radius of $1.96 \AA$, respectively). A fluoride anion is sufficiently small to find space within the trigonal cavities in the C, $\mathrm{N}$ plane (Fig. 6B and D). It does not protrude significantly into the inter-layer space and hence van 

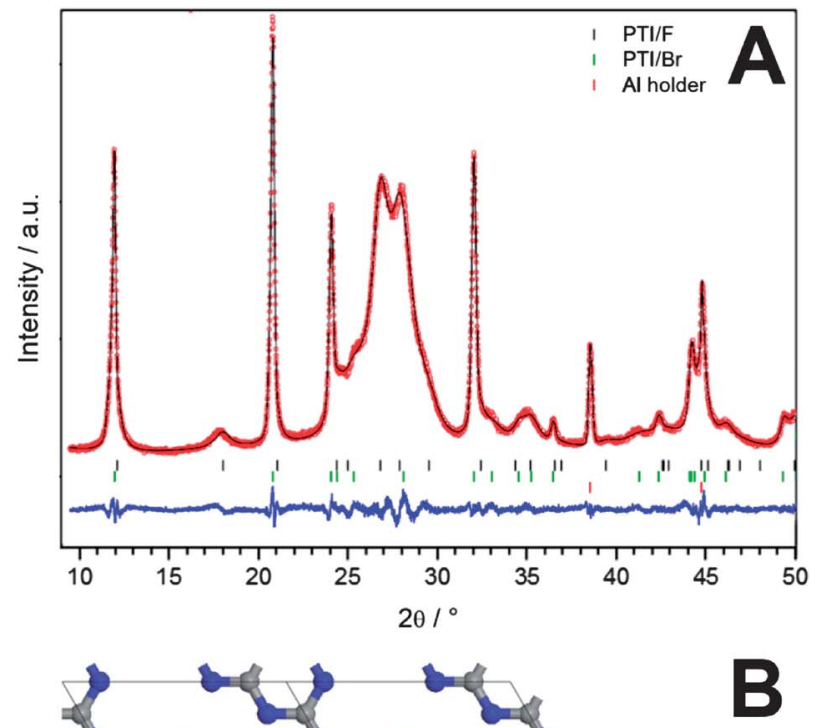

10
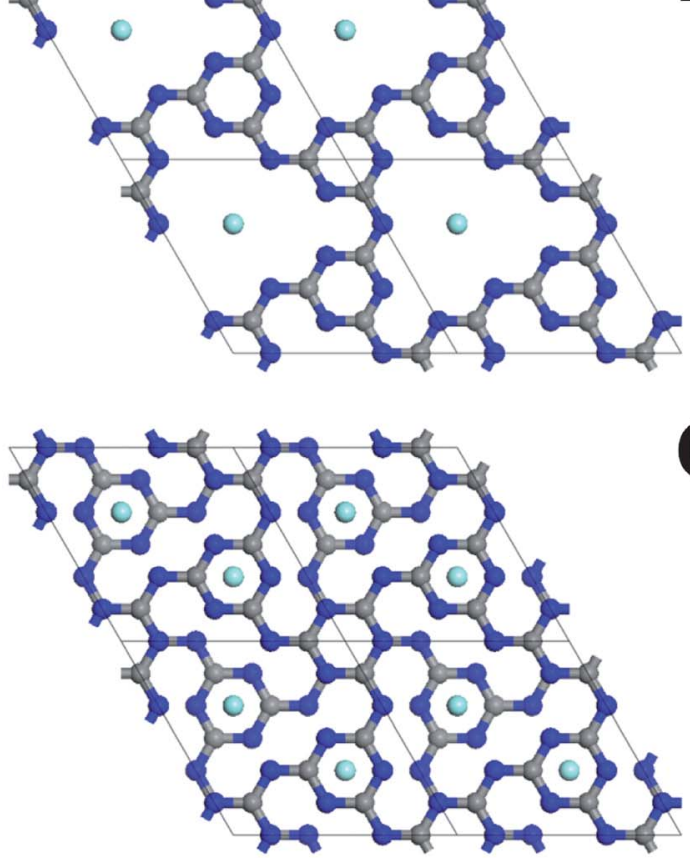

D

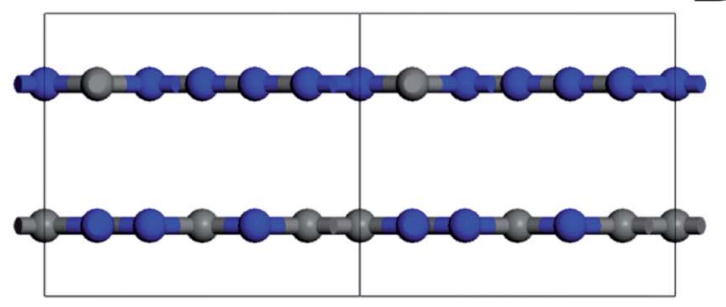

Fig. 6 LeBail fit modelled as a two-phase mixture of PTI/F and PTI/Br with the observed pattern in black, fitted profile in red, and difference plot in blue $\left(R_{\mathrm{wp}}=\right.$ $3.89 \%, R_{p}=3.05 \% \chi^{2}=1.42$ ). Bragg peak positions are shown as dashes in black for $\mathrm{PTI} / \mathrm{F}$, in green for $\mathrm{PTI} / \mathrm{Br}$ and in red for the Al-sample holder, respectively (A). Projection along the $c$-axis of one layer (B) and two consecutive layers (C) of PTI/F with carbon, nitrogen, and fluoride atoms represented as grey, blue, purple and teal spheres, respectively. Projection along the $b$-axis. F-anions are situated within the void-space (D). The parameters of the hexagonal unit cell $\left(P 6_{3} / m\right.$, no. 176$)$ are $a=8.4212(4) \AA, c=6.6381(5) \AA$. der Waals interactions between the $\mathrm{C}, \mathrm{N}$ planes determine the gallery height of PTI/F rather than steric repulsion exerted by the guest.

\section{Conclusions}

The 2D, layered graphitic carbon nitride network-poly(triazine imide) (PTI) — has been obtained as an intercalation compound with the halides bromide (PTI/Br) and fluoride (PTI/F). The yellow-brownish materials both have hexagonal space groups (PTI/Br; $P 6_{3} \mathrm{~cm}$, no. 185 and PTI/F; $P 6_{3} / m$, no. 176) with parameters of $a=8.500390(68) \AA, c=7.04483(17) \AA$ for PTI $/ \mathrm{Br}$ and $a=$ 8.4212(4) $\AA, c=6.6381(5) \AA$ for $\mathrm{PTI} / \mathrm{F}$, respectively, as established by Rietveld refinement, LeBail extraction and HRTEM studies, and are structurally related to $\mathrm{PTI} / \mathrm{Li}^{+} \mathrm{Cl}^{-}, \mathrm{C}_{6} \mathrm{~N}_{9} \mathrm{H}_{3} \cdot \mathrm{HCl}$ and other hypothetical graphitic phases of $\mathrm{C}_{3} \mathrm{~N}_{4}$. On the basis of ${ }^{13} \mathrm{C}$ and ${ }^{15} \mathrm{~N}$ NMR spectra it is confirmed that the unit-cell of intercalated PTI contains two layers of imide-bridged triazine $\left(\mathrm{C}_{3} \mathrm{~N}_{3}\right)$ units stacked in an AB-fashion. Intriguingly, the gallery height of the layered PTI materials varies with the diameter of the intercalated host. In the series of crystal and ionic radii of halogens $\mathrm{X}=\mathrm{F}<\mathrm{Cl}<\mathrm{Br}$ the PTI/X intercalation materials follow the same trend with stacking distances of $3.32,3.38$, and $3.52 \AA$ for PTI/F, PTI/Cl and PTI/Br, respectively. PTI/F shows a gallery height that is smaller than that of graphite $(3.35 \AA$ ), suggesting that the fluoride guest anion is situated in the large voids in the $\mathrm{C}, \mathrm{N}$ plane, while chloride and bromide anions protrude into the interstitial space between the $\mathrm{C}, \mathrm{N}$ planes and hence expand the gallery height according to their radii.

Most significantly, this work shows the relative ease with which tuning of the gallery height of hypothetically infinite, two-dimensional, covalently bonded molecular sheets can be achieved through intercalation of guests. The direct analogy of these $\mathrm{C}, \mathrm{N}$ materials to the carbon-only layered systemgraphite-is striking, and investigations into a potential pathway for the exfoliation of this interesting $2 \mathrm{D}$ material will be presented independently.

\section{Acknowledgements}

The authors thank EPSRC for funding (EP/H000925) and also EPSRC and E.ON for funding (EP/C511794/1) through the E.ONEPSRC strategic call on CCS. A. I. C. is a Royal Society Wolfson Merit Award holder. The Max Planck Society is acknowledged for financial support within the EnerChem network. We thank Diamond Light Source for access to beamline I11, and Dr Julia Parker, Dr Marc Schmidtmann and Dr Tom Hasell for assistance during the experiment.

\section{Notes and references}

1 M. L. Cohen, Phys. Rev. B, 1985, 32, 7988-7991.

2 A. Y. Liu and M. L. Cohen, Science, 1989, 245, 841-842.

3 D. M. Teter and R. J. Hemley, Science, 1996, 271, 53-55.

4 E. Kroke and M. Schwarz, Coord. Chem. Rev., 2004, 248, 493532. 
5 E. Horvath-Bordon, R. Riedel, P. F. McMillan, P. Kroll, G. Miehe, P. A. van Aken, A. Zerr, P. Hoppe, O. Shebanova, I. McLaren, S. Lauterbach, E. Kroke and R. Boehler, Angew. Chem., Int. Ed., 2007, 46, 1476-1480.

6 A. Salamat, K. Woodhead, P. F. McMillan, R. Q. Cabrera, A. Rahman, D. Adriaens, F. Cora and J. P. Perrillat, Phys. Rev. B: Condens. Matter Mater. Phys., 2009, 80, 104106.

7 F. Goettmann, A. Fischer, M. Antonietti and A. Thomas, Chem. Commun., 2006, 4530-4532.

8 F. Goettmann, A. Thomas and M. Antonietti, Angew. Chem., Int. Ed., 2007, 46, 2717-2720.

9 X. Wang, S. Blechert and M. Antonietti, ACS Catal., 2012, 2, 1596-1606.

10 X. Wang, K. Maeda, A. Thomas, K. Takanabe, G. Xin, J. M. Carlsson, K. Domen and M. Antonietti, Nat. Mater., 2009, 8, 76-80.

11 M. Deifallah, P. F. McMillan and F. Cora, J. Phys. Chem. C, 2008, 112, 5447-5453.

12 J. Sakamoto, J. van Heijst, O. Lukin and A. D. Schlüter, Angew. Chem., Int. Ed., 2009, 48, 1030-1069.

13 J. C. Meyer, A. K. Geim, M. I. Katsnelson, K. S. Novoselov, T. J. Booth and S. Roth, Nature, 2007, 446, 60-63.

14 A. K. Geim and K. S. Novoselov, Nat. Mater., 2007, 6, 183-191. 15 P. Kuhn, M. Antonietti and A. Thomas, Angew. Chem., Int. Ed., 2008, 47, 3450-3453.

16 O. M. Yaghi, M. O'Keeffe, N. W. Ockwig, H. K. Chae, M. Eddaoudi and J. Kim, Nature, 2003, 423, 705-714.

17 A. P. Cote, A. I. Benin, N. W. Ockwig, M. O’Keeffe, A. J. Matzger and O. M. Yaghi, Science, 2005, 310, 11661170.

18 J. W. Colson, A. R. Woll, A. Mukherjee, M. P. Levendorf, E. L. Spitler, V. B. Shields, M. G. Spencer, J. Park and W. R. Dichtel, Science, 2011, 332, 228-231.
19 A. Nagai, Z. Q. Guo, X. Feng, S. B. Jin, X. Chen, X. S. Ding and D. L. Jiang, Nat. Commun., 2011, 2, 536.

20 R. C. DeVries, Mater. Res. Innovations, 1997, 1, 161-162.

21 P. H. Fang, J. Mater. Sci. Lett., 1995, 14, 536-538.

22 T. Malkow, Mater. Sci. Eng., A, 2000, 292, 112-124.

23 S. Matsumoto, E. Q. Xie and F. Izumi, Diamond Relat. Mater., 1999, 8, 1175-1182.

24 W. Sundermeyer, Angew. Chem., 1965, 77, 241-258.

25 W. Sundermeyer, Chem. Unserer Zeit, 1967, 1, 150-157.

26 M. J. Bojdys, J. Jeromenok, A. Thomas and M. Antonietti, Adv. Mater., 2010, 22, 2202-2205.

27 M. J. Bojdys, S. A. Wohlgemuth, A. Thomas and M. Antonietti, Macromolecules, 2010, 43, 6639-6645.

28 P. Kuhn, A. Forget, D. S. Su, A. Thomas and M. Antonietti, J. Am. Chem. Soc., 2008, 130, 13331-13337.

29 P. Kuhn, A. Thomas and M. Antonietti, Macromolecules, 2009, 42, 319-326.

30 M. J. Bojdys, J.-O. Mueller, M. Antonietti and A. Thomas, Chem.-Eur. J., 2008, 14, 8177-8182.

31 E. Wirnhier, M. Döblinger, D. Gunzelmann, J. Senker, B. V. Lotsch and W. Schnick, Chem.-Eur. J., 2011, 17, 32133221.

32 J. George, Molten Salts Handbook, Academic Press, London, 1967.

33 P. F. McMillan, V. Lees, E. Quirico, G. Montagnac, A. Sella, B. Reynard, P. Simon, E. Bailey, M. Deifallah and F. Cora, J. Solid State Chem., 2009, 182, 2670-2677.

34 Z. Zhang, K. Leinenweber, M. Bauer, L. A. J. Garvie, P. F. McMillan and G. H. Wolf, J. Am. Chem. Soc., 2001, 123, 7788-7796.

35 L. H. Ahrens, Geochim. Cosmochim. Acta, 1952, 2, 155-169.

36 L. Pauling, The Nature of the Chemical Bond, Cornell University Press, Ithaca, 1960. 